\title{
Development of Biobriquette from Nutmeg Seed Shells
}

\author{
Rukmana Idris ${ }^{1+}$, Ahmad Tawiequrrohman Yuliansyah $^{1}$, Suryo Purwono ${ }^{1}$ \\ ${ }^{1}$ Department of Chemical Engineering, Faculty of Engineering, Universitas Gadjah Mada, Indonesia
}

\begin{abstract}
Nutmeg seed shell is one of biomass resources in Indonesia that has not been widely used. Nutmeg (Myristicafragans) in North Maluku province, especially in Tidore Island, is one of the largest incomes in the plantation sector. Nutmeg consists of pulp, mace, shell and seeds. Not all parts of nutmeg can be utilized or to be sold. The most widely used are the seed, mace (red salute that bind shell beans) and meat of nutmeg, while some parts have not been used optimally such as the shells. The abundance of nutmeg seed shells has only been discarded and not optimally utilized, therefore it needs to do a research on the utilization of nutmeg seed shells into briquettes that have good quality, which can be used as energy source and improve economic value. One fo the solutions is by converting it into bio briquette through pyrolysis process. Pyrolysis is chemical decomposition of organic materials through a process of heating without oxygen or under conditions of a little air, causing the release of volatiles and char formation. If the material contains water, at the beginning of heating, the free water will come out first at a temperature of about $120^{\circ} \mathrm{C}$. Up to $170^{\circ} \mathrm{C}$, volatile organic substances from hydrolysis will be released out. The conditions affect pyrolysis processes are temperature, heating time and particle size. The higher the temperature the higher the rate of decomposition.
\end{abstract}

\section{Introduction}

Bio-briquette are bio fuel substitute to coal and charcoal, mostly made of green waste and other organic materials, are commonly used for electricity generation, heat, and cooking fuel. Bio-briquettes are the solid fuel that compressed and have a specific shape. These compressed compounds contain various organic materials, including rice husk, bagasse, ground nut shells, municipal solid waste, agricultural waste. The composition of briquettes varies by area due to the availability of raw materials. The raw materials are gathered and compressed into briquette in order to burn longer and make transportation of the goods easier. These briquettes are very different from charcoal because they do not have large concentrations of carbonaceous substances and added materials. Compared to fossil fuels, briquettes produce low net total greenhouse gas emissions because the materials used are already a part of the carbon cycle.

Moisture content in the briquettes is between 10-20\% by weight. Sizes of briquette vary from 20-100 grams. Some of briquettes are commonly known as pillows (oval), beehive (honey comb), cylinder, and others [1]. Some parameters affecting the quality of briquettes are calorific value, fixed carbon, moisture content, ash content and volatile matter. The higher the calorific value and fixed carbon, the lower the ash content, water content and volatile matter in briquettes is good quality briquettes. The parameters must fulfill of standards quality from SNI NO. $1 / 6235 / 2000$ with moisture content $\leq 8 \%$, ash content $\leq 8 \%$, volatile matter $\leq 15 \%$, fixed carbon $\geq 77 \%$ and calorific value $\geq 5000 \mathrm{cal} / \mathrm{g},[2]$.

Pyrolysis is chemical decomposition of organic material through a heating process with little or no oxygen or reagent. In this condition, the structure of raw material will undergo breakdown into the gas phase. Pyrolysis includes the case of thermolysis. Conditions affect of the pyrolysis process are temperature, heating time and particle size. Higher temperature will increase the rate of thermal decomposition.

Nutmeg seed shell is one of biomass resources in Indonesia that has not been widely used. Nutmeg (Myristicafragrans) in North Maluku province, especially in Tidore Island is one of the largest incomes in the plantation sector. The percentage wet weight of nutmeg parts is the meat of nutmeg $(77.8 \%)$, mace $(4 \%)$, shells $(15.1 \%)$ and seeds (13.1\%) [3].One of the factors of nutmeg can be utilized as a briquette is the contain of lignocelluloses which are hemicelluloses (9.51\%), cellulose (28.63\%) and lignin (50.14\%).

During the pyrolysis process as result of heating, several reactions can occur. However, to simplify the 
calculation, we use a modification of three-step mechanism [4].

Modification of three-step mechanism follows the equation:

$$
\begin{gathered}
\frac{d K}{d t}=-\left(\mathrm{k}_{1}+\mathrm{k}_{2}+\mathrm{k}_{3}\right) \mathrm{K} \\
\frac{d G}{d t}=\mathrm{k}_{1} \mathrm{~K} \\
\frac{d C}{d t}=\mathrm{k}_{2} \mathrm{~K} \\
\frac{d P a}{d t}=\mathrm{k}_{3} \mathrm{~K}
\end{gathered}
$$

Constant of reaction rate follows the Arrhenius equation as below:

$$
k=\mathrm{A} \exp \left(-\frac{E}{R T}\right)
$$

\section{Methodology}

\subsection{Preparation of Raw Materials}

The raw materials are nutmeg seeds shells that dried under the sun. After that, the size of nutmeg seeds shells is diminished by a crusher and then sieved with a sieve size of 20 mesh.

\subsection{Pyrolysis}

Nutmeg powder was put into an oven at temperatures between $90-105^{\circ} \mathrm{C}$, for about one hour to remove the remaining water. After that, the powder was put into a retort to be pyrolyzed at a temperature between $250-$ $500^{\circ} \mathrm{C}$. The pyrolysis time varied from 30 to 90 minutes. The products of pyrolysis were gas, liquid and solid. The solid was then removed from the reactor and mixed sticky with material and then pressurized up to 4 tons to form bio briquette. Fig. 1 shows the schematic diagram of the pyrolysis process.

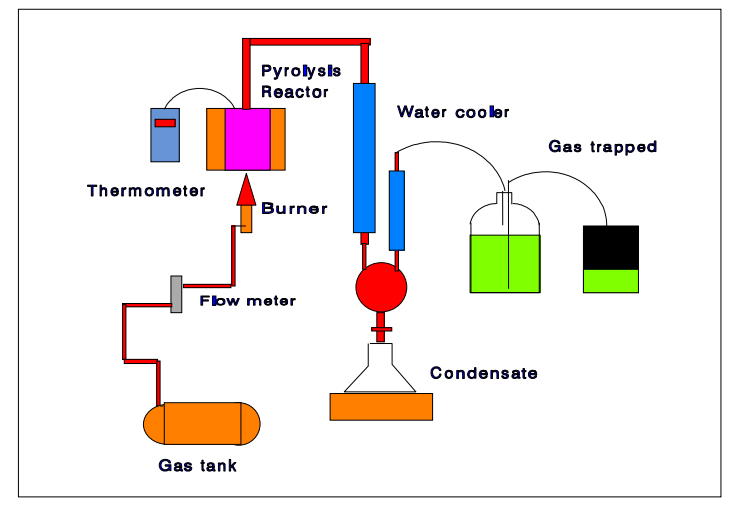

Fig. 1. Equipment for the pyrolysis experiment.

\subsection{Briquetting Process}

For the briquetting process, nutmeg seeds shells were pyrolyzed up to $350{ }^{\circ} \mathrm{C}, 400^{\circ} \mathrm{C}$, and $450^{\circ} \mathrm{C}$ for 90 minutes.
During pyrolysis process, the volumes of liquids and gasses were measured every 15 minutes. At the $60^{\text {th }}$ minute of the pyrolysis process, gas samples were taken and stored in a vacuum tube to analyze its levels of $\mathrm{CO}$, $\mathrm{CO}_{2}$ and $\mathrm{CH}_{4}$ contained. The gas pressure was measured using a manometer open. After pyrolysis, charcoal of nutmeg seeds shell was weighed 20 grams. Then it was mixed with adhesive with the variation $\%$ by weight of the adhesive with nutmeg seeds shells 10: 90\%, 15: 85\%, 20: $80 \%, 25: 75 \%$ and $30: 70 \%$. After that, it was pressed into a cylindrical shape and then compressed by a hydraulic press with a compression pressure of 3 tons for 1 minute. Compressed briquette was then dried using an oven at a temperature of $\pm 60-80^{\circ} \mathrm{C}$.

\subsection{Research Variable}

Fixed variable consisted of pyrolysis time for 90 minutes and a particle size of 20 mesh. While the independent variable is the pyrolysis temperature of $350^{\circ} \mathrm{C}, 400^{\circ} \mathrm{C}$ and $450^{\circ} \mathrm{C}$ and weight of adhesive mixtures of starch was $10 \%, 15 \%, 20 \%, 25 \%, 30 \%$.

\subsection{Analysis of the Results}

Yield of products were analyzed using the following equation:

$$
\mathrm{Y}=\frac{W(G / C / P a)}{W 0} \times 100 \%
$$

Analysis of the gas content of $\mathrm{CO}, \mathrm{CO}_{2}$, and $\mathrm{CH}_{4}$ that comes out during pyrolysis was analyzed using gas chromatography (GC) on Instrumental Analytical Laboratory in Chemical Engineering Department UGM. In addition, to determine the quality of nutmeg seeds shells briquettes, several analysis were done such as calorific value, moisture content, volatile matter, fixed carbon, ash content at the laboratory of the Food and Nutrition in University Centre UGM. To determine the strength of the briquettes, we use shatter indexes test or drop test using ASTM D 440-86 R02 method.

\section{Results and Discussion}

\subsection{Characteristics of Raw Materials}

Briquette is a solid fuel that is made from organic material and has a specific shape. Based on the analysis results, nutmeg seed shells has an ash content of $1.119 \%$, moisture content of $10.256 \%$, volatile matter of $58.423 \%$, fixed carbon of $30.712 \%$, and calorific value of 4339.861 $\mathrm{cal} / \mathrm{g}$.

\subsection{Effect of temperature to yield product}

Thee effect of temperature to yield a product of gasses, liquids, and solids when the temperature of operation gets 
higher, the decomposition will increases. Yield product can be seen in Fig. 2.

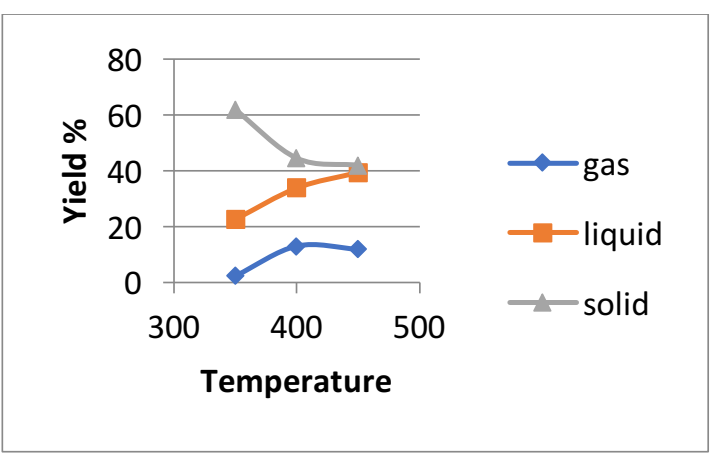

Fig. 2. Yield product

The rise in temperature will increase the rate of decomposition such as water content and volatile compounds, it causes fluid production increased at a higher temperature.

\subsection{Pyrolysis Reaction Kinetics}

The mechanism used is a three-step mechanism by Erawati et al (2013). This model depicts the solids mass reduction, the increase in mass of gas and liquid pyrolysis against time. Fig. 3 shows the comparison of gas and liquid by calculating the equation of reaction kinetics.

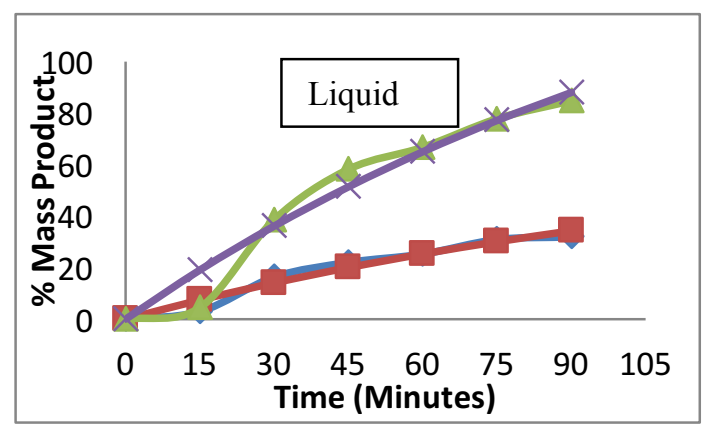

Fig. 3. Effect of time on the result of gas and liquid at temperature $350^{\circ} \mathrm{C}$

According to Shankar et.al. (2010), the increased mass of gas and liquid is due to the breakdown of the chain on the lignocelluloses compounds that occur gradually. At the beginning of heating the short-chain will be degraded early and then the long chain would be degraded causing an increased mass of gas and liquids significantly.

The value of pre-exponential (A) and the activation energy $(\mathrm{Ea})$ are $\mathrm{k}_{1}(4.77 \mathrm{~min}-1,27.89 \mathrm{KJ} / \mathrm{mol}), \mathrm{k}_{2}(0.518$ $\min -1,11.59 \mathrm{KJ} / \mathrm{mol})$ and $\mathrm{k}_{3}(6,36 \times 10-4 \mathrm{~min}-1,11.22$ $\mathrm{KJ} / \mathrm{mol}$ ). The values of activation energy of nutmeg seed shells briquettes are not much different from the activation energy of straw which is $11.3(\mathrm{KJ} / \mathrm{mol})$ [5].

\subsection{Gas Analysis}

Analysis of $\mathrm{CO}, \mathrm{CO}_{2}$ and $\mathrm{CH}_{4}$ gasses in the pyrolysis process can be seen in Fig. 4:

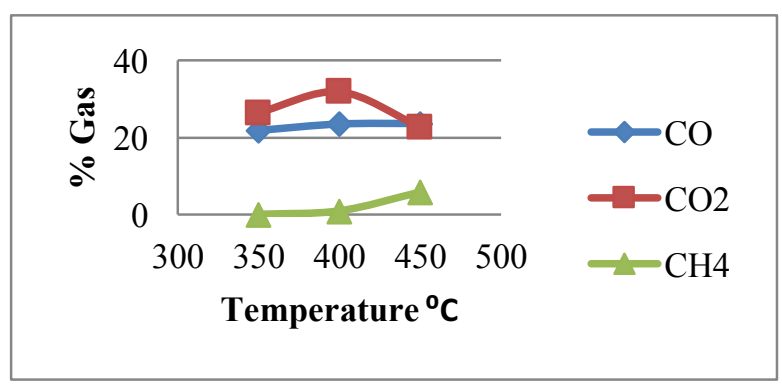

Fig. 4. Effect of temperature on gas analysis

According to Varfolomeev and Grachev (2015), the reason for increasing the production of $\mathrm{CH}_{4}$ because of the lignin begins to decompose at above $350^{\circ} \mathrm{C}$. The same thing for the production of $\mathrm{CO}$, where it is increased when the temperature pyrolysis is high. These results are similar as reported by Ion (2013). However, the values of $\mathrm{CO}_{2}$ is different, which increases at $400^{\circ} \mathrm{C}$ and decrease at temperature $450^{\circ} \mathrm{C}$.

\subsection{Quality of Briquette}

The lower moisture content, ash content and volatile matter contained in the briquettes, the quality of briquettes increase. According to SNI No. 1/6235/2000 standard, the moisture content and ash content should be less than $8 \%$, while the volatile matter is less than $15 \%$. Based on the experiment the lowest value of moisture content before being mixed with the adhesive is at $400^{\circ} \mathrm{C}$. This is different with the experiment at $450^{\circ} \mathrm{C}$ which has a value of water content is higher. In the study of Sastry et al. and Sengar et al. (2012) these things happen because it is influenced by the type of storage affect of the absorption of water from the air, and also causes the temperature of the air humidity which affects the water content. While the maximum ash content in $450^{\circ} \mathrm{C}$ is $11.252 \%$, the value is not yet met the standard of SNI No. 1/6235/2000.

High value of volatile matter can degrade the quality of briquettes since it lowers the content of fixed carbon and can also affect the calorific value produced. Besides it will cause in increasing the amount of smoke produced from burning [6]. Low volatile matter contained in the results of $450^{\circ} \mathrm{C}$ is $8.385 \%$ without the addition of adhesives and already meet the ISO Standard No. $1 / 6235 / 2000$.

Shatter index is a test to measure the strength of briquette due to impact. The results of the test show that shatter indexes at $400^{\circ} \mathrm{C}$ and $450^{\circ} \mathrm{C}$ of briquettes are less than at $350^{\circ} \mathrm{C}$, it is also caused by high fixed carbon and the addition of adhesive as well. Higher adhesive content in the briquettes makes briquettes stronger, proves that the briquettes with $30 \%$ adhesive have the highest Shatter Index.

\subsection{Environmental and Economic Aspects}

Utilization of nutmeg seed shells as briquettes is one way to reduce the abundant of nutmeg seed shells that increase during harvest. Based on the literature, nutmeg production 
in 2013 is up to 225 tons and shells weighing 71.4 tons which are $28 \%$ of the production of nutmeg. The weight of the shells after converted into charcoal was reduced by $44.4 \%$, is 31.7 tons of which were used as the raw material of briquettes. That shows that the utilization as briquettes can reduce waste of nutmeg seed shells.

While fro the economic aspect, people of Tidore mostly use kerosene and firewood as the main fuel for cooking needs. The results showed that the nutmeg seed shell briquettes have higher calorific value than wood with a relatively cheap price which is around Rp.4000 / $\mathrm{kg}$.

\section{Conclusion}

1. The three-step mechanism depicts the solids mass reduction

2. When the temperature of operation is increased, the decomposition processes are getting better where the product of gasses and liquid increase.

3. The quality of the briquette partly fulfills the standard of SNI

\section{Acknowledgements}

The authors are grateful for funding from Directorate General of Higher Education (DP2M-Dikti) and from Chemical Engineering Department, Universitas Gadjah Mada.

\section{Nomenclature}

$\mathrm{K}=$ initial of biomass

$\mathrm{k} \quad=$ Arrhenius

$\mathrm{k}_{1} \quad=$ Arrhenius constant for gas

$\mathrm{k}_{2} \quad=$ Arrhenius constant for liquid

$\mathrm{k}_{3} \quad=$ Arrhenius constant for solid

$\mathrm{t}=$ time of reaction

$\mathrm{A}=$ collision constant

$\mathrm{E} \quad=$ activation energy

$\mathrm{R}=$ gas constant

$\mathrm{T}=$ temperature

$\mathrm{G} \quad=$ gas

$\mathrm{C}=$ liquid

$\mathrm{Pa} \quad=$ solid

$\mathrm{W}=$ weight

$\mathrm{Y} \quad=$ yield

\section{References}

1. A.C. Brades, F.S. Tobing, Development of Briquette from Eichornia Crasipess Solm, Chemical Engineering Department, Sriwijaya University, Palembang (2007)

2. Paisal, M.S. Karyani, Quality Analysis of Biobriquette from Durian Skin, Ambon Polytechnic (2014)
3. N. Nurdjannah, Nutmeg Processing Technology, Agriculture Department (2007)

4. E. Erawati. W.B. Sediawan, Modification of the Mechanism in Pyrolysis Kinetic Reaction of Bagasse, Chemical Engineering Department, Universitas Gadjah Mada (2013)

5. J.O. Adekunle, J.S. Ibrahim, E.I. Kucha, Br.J. Appl.Sci.Technol 7, 114-123 (2015)

6. S.J. Veeresh, J. Narayana, Univ. J.Envi. Res.Tech 2, 575-581 (2012)

7. M.K. Sastry, J. Bridge, A. Brown, R. Williams, Biomass Briquette : A Sustainable and Environment Friendly Energy Option for the Caribbean, Fifth International Symposium on Energy, Puerto Rico Energy Center-Laccei Puerto Rico (2013)

8. S.H. Sengar, A. Mohod, Y. Khandetod, S. Patil, A. D. Chendake, Intl. J. Energy Engineering 2, 28-34 (2012)

9. J.S. Tumuluru, C.T. Wright, K.L. Kenney, J.R. Hess, A Technical Review on Biomass Processing: Densification, Prepocessing, Modeling, and Optimization, 3-5 (2010)

10. M. Varfolomeev, A. Grachev, Thermal Analysis and Calorimetric Study of The Combustion of Hydrolytic Wood Lignin and Products of Its Pyrolysis, Kazan National Research Technological University (2015) 